\title{
ANTONIONI E AS FIGURAS DO TEMPO
}

\author{
Solange Puntel Mostafa ${ }^{1}$ \\ Universidade de São Paulo - USP \\ smostafa@terra.com.br \\ Igor Soares Amorim ${ }^{2}$ \\ Universidade Federal de Santa Catarina \\ amorim.igors@gmail.com
}

\begin{abstract}
Resumo
Explora as noções deleuzinas sobre o cinema e problematiza elementos relacionados a indexação de filmes. Aprofunda as questões cinematográficas trabalhadas por Deleuze, que concebe dois principais regimes de imagens, compreendidos no cinema clássico e no cinema moderno. O cinema clássico é fundado na imagem-movimento, a qual submete o tempo à ação, já o cinema moderno, caracteriza-se pela imagem-tempo, a qual desvincula tempo e movimento e revela situações óticas e sonoras puras. Analisa o problema do tempo em três filmes dirigidos por Michelangelo Antonini, conhecidos como trilogia da incomunicabilidade, A Aventura (1960), A Noite (1961) e O Eclipse (1962). A partir da análise de filmes sob a abordagem deleuziana é possível ampliar as dimensões presentes na indexação, tanto no processo de leitura quanto de análise do documento, considerando a dimensão do afeto.
\end{abstract}

Palavras-chave: Indexação. Imagem-movimento. Imagem-tempo. Cinema. Antonioni.

\section{ANTONIONI AND THE IMAGES OF TIME}

\begin{abstract}
We explore the deleuzians notions on the cinema and problematizes elements related to the indexation of films. We delved into the cinematic issues worked out by Deleuze, who conceives two major regimes of images, comprised in classical cinema and modern cinema. The classical cinema is based on the movement-image, which submits time to action, and the modern cinema, is characterized by the time-image, which dissociates time and movement and reveals pure optical and sound situations. We analyze the problem of time in three films directed by Michelangelo Antonini, known as the trilogy of incommunicability, The Adventure (1960), The Night (1961) and The Eclipse (1962). From the analysis of films under the Deleuzian approach it is possible to expand the dimensions present in the indexing, both in the reading process and in the analysis of the document, considering the dimension of affection.
\end{abstract}

Keywords: Indexing. Movement-image. Time-image. Cinema. Antonioni.

1 Graduação em Biblioteconomia e Documentação pela Escola de Biblioteconomia e Documentação de São Carlos (1972), Mestrado em Ciência da Informação pelo Instituto Brasileiro de Informação em Ciência e Tecnologia (1981) e Doutorado em Educação (Filosofia da Educação) pela Pontifícia Universidade Católica de São Paulo (1985), com experiência de Pós-Doutorado na Inglaterra, PNL, Londres.

${ }^{2}$ Formado em Ciências da Informação, Documentação e Biblioteconomia pela Universidade de São Paulo. Integrante do programa de pós-graduação em Ciência da Informação da Universidade Federal de Santa Catarina. É representante discente e membro do conselho fiscal da Associação Nacional de Pesquisa e Pós-Graduação em Ciência da Informação (Ancib).

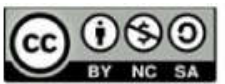

Esta obra está licenciada sob uma Licença Creative Commons Atribuição 4.0 Internacional (CC BY-NC-AS 4.0). LOGEION: Filosofia da informação, Rio de Janeiro, v. 5 n. 1, p.102-119, set.2018/fev. 2019 


\section{OS PLANOS FILOSÓFICOS E ARTÍSTICOS}

Ninguém necessita da filosofia para refletir. Não precisamos da filosofia para refletir sobre as artes, sobre as imagens, sobre o cinema. A arte pensa por si mesma, assim como a filosofia e também a ciência. O cinema pensa por si mesmo, como nos mostra Deleuze em seus dois livros sobre a sétima arte, "Cinema-1: imagem-movimento" (1983) e "Cinema-2: imagemtempo" (1985).

Enquanto filósofo, Deleuze não faz uma crítica da arte, mas cria conceitos. Conceitos filosóficos que capturam o caos em sua dinamicidade e nos faz pensar. A arte, assim como a filosofia também enfrenta o caos e nos força a pensar, porém por meio de sensações, e não mais por conceitos. Da mesma forma, a ciência, que pensa por funções e proposições. Por mais poética que sejam as obras filosóficas escritas por Deleuze, o francês faz filosofia. Mas questionamos: por que o francês se utiliza da literatura, da pintura, da música, do teatro e de tantas outras artes para filosofar? A resposta é que a filosofia precisa ser agenciada com o nãofilosófico para criar conceitos. O mesmo vale à arte, que se conecta com o não-artístico para inovar, e a ciência com o não-científico.

Contudo, é preciso afirmar que arte, ciência e filosofia não se confundem em seus processos, cada uma enfrenta o caos e a doxa à sua maneira. A filosofia, na criação do conceito, constrói um plano filosófico sobre o caos, espalhando nele qualidades intensivas do próprio caos por meio de personagens conceituais. A ciência traça um plano de referência sobre o caos, no qual desacelera as intensidades e as inter-relacionam, de forma a estabelecer funções e proposições. A arte cria seus blocos de sensação num plano, o qual captura uma imagem do caos por meio de personagens estéticas. Assim, arte, ciência e filosofia pensam (DELEUZE; GUATTARI, 2010).

Deleuze conecta a filosofia ao cinema a fim de criar conceitos sobre um plano filosófico. Ele afirma na conferência "o que é o ato de criação?", que o limite comum entre cinema e filosofia é o espaço-tempo. A filosofia cria a Ideia através de conceito, e o cinema cria a Ideia por meios de seus recursos técnicos que expressam sensações via imagens (blocos de movimento-duração) (DELEUZE, 1999).

Quando dialoga com a arte ou a ciência, Deleuze busca um contato com o "nãofilosófico" a fim de criar conceitos, assim sua criação filosófica se dá pelo deslocamento entre planos, entre os planos científico, artístico e filosófico. Neste trabalho pretendemos explorar o cinema do diretor italiano Michelangelo Antonini, especificamente sua trilogia da incomunicabilidade, sob uma perspectiva deleuziana, a fim de tocar no problema do tempo e, a 
partir disso, pensar deslocamentos para o plano referencial da Ciência da Informação, especificamente na questão sobre a indexação desses filmes.

\section{AS IMAGENS CINEGRÁFICAS}

Cinema é um termo que remete ao movimento, mas especificamente a captura de imagens que representam mecanicamente o movimento. Tal representação se dá mediante uma narrativa constituída por imagens e sons e que podem apresentar-se genericamente sob perfil ficcional ou documentário. O cinema produz filmes e, com isso, pensa cinematograficamente. O cinema é uma forma de pensamento, na qual os cineastas são seus pensadores. Enquanto a filosofia pensa por conceitos, o cinema o faz via imagens, isto é, os problemas cinematográficos são trabalhados por imagens.

A sétima arte concebe uma Ideia cinematográfica, isto é, um problema é expresso cinematograficamente, como a "urgência daquilo que ainda não sei" em Kurosawa, ou a (des)conexão entre fragmentos de espaços em Bresson (DELEUZE, 1999). Para Deleuze, o cinema pensa por imagens, das quais ele explicitou três principais: a imagem-movimento, a imagem-tempo e a imagem-cristal. O que distingue cada imagem é a relação que se estabelece entre o movimento e o tempo. Cada uma dessas imagens apresenta um tipo de relação. Deleuze parte basicamente de dois tipos gerais de imagens: a imagem-movimento, caracterizada pela submissão do tempo ao movimento, e a imagem-tempo, que liberta o tempo do movimento. A partir dessas, Deleuze compreende duas manifestações cinematográficas, o cinema clássico, baseado em imagens-movimento, e o cinema moderno, baseado em imagens-tempo. Imagensmovimento e imagens-tempo são as formas pela qual o cinema pensa.

As noções de ambas imagens estão pautadas em três teses sobre o movimento afirmadas por Bergson. A primeira diz que movimento e espaço não se confundem, então, o cinema pode representar o espaço, a trajetória, contudo não pode representar o movimento de forma orgânica. A representação cinematográfica do movimento é artificial, contudo, sua percepção pelo espectador não o é, pois o espectador apreende cada imagem em conexão com o movimento, por isso o conceito: imagem-movimento. A segunda tese define uma forma atualizada de compreender o movimento, sem a necessidade de pontos fixos, na qual o tempo é entendido como duração, sem necessariamente um início e um fim. Assim, o movimento é tomado como um corte na duração. A terceira tese afirma que o movimento se revela sob dois aspectos, é o que se passa entre partes ou objetos e, igualmente, é o que exprime um todo, a duração. Pelo movimento, o todo se divide em partes e as partes se reúnem no todo (MACHADO, 2009). 
Para Bergson, há identidade entre imagem e movimento. O filósofo desenvolve uma teoria do conhecimento não representacionista, na qual imagens, enquanto aquilo que nos aparece, identificam com ações e reações, isto é, os movimentos. Dessa forma, as imagensmovimento estão em variação perpétua, umas em relações às outras, pois elas agem e reagem entre si. O conjunto de imagens-movimento em interação e inter-reação constitui o universo material que preexiste aos corpos, as qualidades e as ações. Tal universo é por sim mesmo luminoso, isto é, não requer um sujeito que ilumine a materialidade do universo. A consciência não está dissociada das imagens-movimento, pelo contrário, é compreendida como produto destas, e surge quando imagens formam uma tela preta com capacidade de refletir a luz característica da materialidade do universo. Entre os movimentos de ação e reação, isto é, entre essas imagens, ocorrem outras imagens, imagens de intervalo. Estas imagens não agem ou reagem, elas estabelecem uma outra maneira de movimentar-se, de forma a organizar os movimentos de ação e reação, elas não são luminosas, mas opacas e funcionam como um anteparo para refletir as imagens de ação e reação (MACHADO, 2009; MOSTAFA; MANINI, 2017b). A partir dessas noções bergsonianas sobre a imagem e o movimento, Deleuze (2005) afirma serem três diferentes as espécies de imagens-movimento: a imagem-percepção, a imagem-afecção e a imagem-ação.

Segundo Deleuze, estas variações de imagens permitem uma compreensão do cinema por meio da noção de imagem-movimento, a qual apresentar indiretamente o tempo a partir da composição cinematográfica. A composição de imagens-percepção, afecção e ação define o cinema clássico, já que este encadeia as imagens em função da ação. A imagem-percepção é uma imagem especial, viva, isto é, concebida entre ação e reação, e constitui-se pela formação de uma subjetividade que reflete a luminosidade da matéria e assim gera um enquadramento, uma percepção possível. No filme, esta imagem se caracteriza por uma forma que estabelece a montagem e a enunciação. A percepção implica numa reação, isto é, na imagem-ação, a qual se compõe em função da distância entre o objeto percebido e a subjetividade que o percebe. A imagem-ação atualiza as qualidades (o reflexo) no meio, e encarna o afeto (potência intensiva) no comportamento. Assim como a imagem-percepção, a imagem-ação também é uma imagem viva, especial e, entre essas duas, Deleuze concebe a imagem-afecção, a qual ocupa sem preencher o espaço entre percepção e ação, e caracteriza esse movimento como expressão. Para Deleuze, a imagem-afecção é o close, o rosto, que apresenta o aspecto reflexivo e o intensivo. A imagem-movimento, com suas três principais variantes, constitui o esquema sensório-motor, isto é, se constituem em situações em que as percepções se prolongam em ação/reação, e que 
compreendem o tempo submetido aos movimentos. Essa é a estrutura do cinema clássico (DELEUZE, 1985; 2005).

Todavia, tal esquema é posto em cheque por uma nova concepção cinematográfica, o cinema moderno. Neste, no esquema sensório-motor somos impedidos de prolongar a percepção até a ação, pois lidamos não mais com imagens-movimento. Agora lidamos com situações óticas e sonoras puras, o que faz da relação do cinema com o tempo mudar de natureza, já que o tempo é liberado do movimento. Então, o cinema não é o mesmo, agora ele alcança pensamentos que a imagem-movimento não pode chegar. Caracterizada pela submissão do tempo ao jogo de percepção-ação, a imagem-movimento tem seu espaço questionado por um novo tipo de figura, a imagem-tempo. O cinema clássico é marcado pela ação, esta é o resultado da conjunção de imagens-movimento. Já, o cinema moderno é um cinema visionário, mediante a nos apresentar às situações sonoras e visuais puras que fazem a coisa em si mesma emergir (DELEUZE, 1985; 2005).

O neorrealismo italiano é um dos criadores do cinema moderno. Pensadores como Roberto Rossellini, Vittorio De Sica, Federico Fellini e Michelangelo Antonioni criaram um novo estilo cinematográfico, que não se pauta na ação, mas em situações óticas e sonoras, as quais nos revelam algo de insuportável e que excede as capacidades do esquema sensóriomotor, essas situações revelam o imperceptível. Antonioni constrói um cinema de tempos mortos e espaços vazios (MACHADO, 2009), por meio de cenas de natureza-morta e cenários desérticos, nas quais o tempo se mostra imutável e independente das relações sensório-motoras. As situações óticas e sonoras puras subordinam o movimento ao tempo e faz o olho adquirir a função de vidente do tempo.

Para Deleuze (2005), a imagem-tempo concebe uma face dupla de uma imagem atual e outra virtual, uma dupla face indissociável, embora difiram em natureza. Essa dupla face é pensada como um cristal do tempo, assim o filósofo aprofunda o estudo sobre imagem-tempo, abordando-a por imagem-cristal. A imagem-cristal apresenta uma imagem atual que têm um reflexo virtual. Há uma cristalização do tempo nesse duplo da imagem-tempo e é nesse processo de cristalização que o tempo submete o movimento, o que resulta no aparecimento do tempo diretamente. Enquanto no cinema clássico o esquema sensório-motor estabelece um regime orgânico fundado na ação, o cinema moderno baseia-se em um regime cristalino.

Atual e virtual aparecem na imagem-cristal em função do tempo. Para revelar isso, Deleuze (2005) retoma os três paradoxos do tempo de Bergson: a) passado e presente não são sucessivos, mas coexistente no tempo e é essa coexistência é chamada de duração; b) passado e presente diferem de natureza, pois o presente é o puro devir e não pára de passar, e o passado 
se conserva em si mesmo e sempre mantém seu ser; c) o tempo desdobra-se constantemente em presente que passa e passado que conserva-se. A partir disso, Deleuze afirma o passado como o virtual e o presente com atual. O próprio presente tem um presente virtual, isto é um passado do presente, que faz do passado puro um possível ao presente. O cinema moderno é uma forma de resgate desse passado puro, pois apresenta o tempo diretamente por meio da imagem-cristal, que conjuga um presente atual e um virtual, um presente e um passado. Não se trata do tempo empírico, cronológico, que submete-se ao movimento, mas o tempo em pessoa, em uma abordagem ontológica. $\mathrm{O}$ vidente vê o cristal do tempo enquanto unidade cindida de um presente e um passado.

Com base na noção nietzschiana de potência do falso, o filósofo francês revela de que forma a descrição, a narração e a narratividade fílmica se manifestam na imagem-movimento e na imagem-tempo. A descrição orgânica diz que a realidade que preexiste à câmera e que independe do objeto, e estabelece ao esquema sensório-motor. A descrição cristalina vale por seu objeto, e remete a situações óticas e sonoras puras de modo a não submeter-se à uma realidade predefinida, mas afirma o real que não está vinculado com o prolongamento motor. A narração orgânica desenvolve uma história sob o esquema sensório-motor; enquanto que a narração cristalina provoca o devir nos personagens, tornando-os videntes, o que os fazem promover movimentos falsos, aberrantes e independentes do tempo, que nos mostra a dissipação do centro da história e a desproporção das escalas, ou seja, a narração não mais comprometesse com a verdade, tornasse falsificadora (substitui a forma do verdadeiro pela potência do falso). A narrativa diz respeito à relação sujeito-objeto nas imagens, sendo que a narrativa orgânica reforça as distinções entre imagens subjetivas e objetivas, enquanto que a narrativa cristalina confunde-as, tal como Pasolini procura desenvolver uma imagem subjetiva indireta livre, com base na noção de bakthiniana de discurso indireto livro. Neste, a câmera capta o mundo subjetivo da personagem ao mesmo tempo em que fornece um ponto de vista específico, o qual incide no próprio mundo da personagem. Segundo Deleuze, a potência do falso atinge seu ápice no cinema nouvelle vague e no cinema de Orson Welles. Conforme Machado (2009, p. 287), "no regime cristalino da imagem, as descrições tornam-se puras, as narrações, falsificadoras, as narrativas, simulações”.

A ruptura com o esquema sensório-motor nos impõe uma questão ética, pois ela significa também o rompimento da crença do homem no mundo em que vive, já que a imagemtempo nos coloca diante do intolerável, e condiciona a impossibilidade do pensamento. $\mathrm{O}$ cinema moderno revela essa impotência de pensar. A saída da questão se dá por meio de outra crença, a crença no impensável. E, se por um lado, o cinema moderno revela a impossibilidade, 
também possibilita o enlace do homem com o impensável, de forma a abrir à novos horizontes de pensamento e da própria noção de vida (DELEUZE, 2005).

Com isso, de acordo com Machado (2009), Deleuze destaca quatro pontos éticopolíticos: a) a relação do cinema e do povo: no cinema clássico o povo existe, mesmo que na condição de oprimido, já no cinema moderno, o povo é o que falta, o que está em constante devir, o povo precisa ser inventado, o que fica claro nos filmes de Glauber Rocha; b) a relação do político com o privado: no cinema clássico, a diferença entre as duas esferas é bem delimitada, o que permite uma tomada de consciência que faz passar de uma força social à outra, enquanto que no cinema moderno, as fronteiras entre as esferas perdem sua rigidez e promove a coexistência de diversas realidades sociais, o que inviabiliza uma luta clara, um inimigo definido, uma revolução; c) a relação com o povo: há um povo, proletário, camponês, no cinema clássico, já no cinema moderno, não há povo, mas sempre um povo a ser inventado, povos, no plural, o cinema enfoca a luta das minorias enquanto fragmentos de um povo por vir; e, finalmente, d) diz respeito à enunciação: no cinema moderno, os enunciados são coletivos, dizem respeito ao devir de um povo, de forma a superar a dualidade privado e político, enquanto que no cinema clássico, as enunciações são individuais.

Deleuze afirma algo fundamental na diferença entre o cinema clássico e o moderno: as relações entre as imagens. No cinema clássico o sonoro funciona de modo empírico, isto é, a imagem sonora opera em uma progressão, uma montagem racional, seguindo a imagem visual, estabelecendo relações comensuráveis entre as séries de imagens. Já no cinema moderno, as imagens visuais e sonoras modificam sua relação, não se encadeiam racionalmente, mas se reencadeiam por fragmentação no interstício das imagens, constituídas por séries divergentes, por relações não cronológicas da imagem-tempo, não mais da montagem, mas da mostragem (DELEUZE, 2005).

Nesse sentido, o neorrealismo italiano representa uma importante contribuição no desenvolvimento do cinema moderno. Os cineastas italianos criam situações óticas e sonoras puras, impossibilitando a ação na medida em que prolonga a percepção. O cinema neorrealista eleva a capacidade de ver ao limite e revela o intolerável, o impensável.

\section{AS INCOMUNICABILIDADES DE ANTONIONI}

O cineasta Michelangelo Antonioni, nascido em Roma no início do século XX e formado em economia, considerava-se um marxista e passou a gravar seus filmes ainda na década de 1940. Diferente do cinema neorrealista italiano de sua época, Antonioni não está 
preocupado em problematizar as questões "proletárias", pelo contrário, vemos em seus filmes a burguesia italiana exposta. Talvez aí o elemento que aproxime o cinema antonioniano do marxismo dos anos de 1960, a linha narrativa se constitui pela noção de alienação, uma aproximação tímida pois Antonioni estava mais empenhado em uma crítica da moral em termos nietzchinianos, conforme pontua Deleuze (2005). Os filmes de Antonioni revelam a alienação da burguesia, fria, perdida, sem esperança ou rumo, que pressente o fim e que está imobilizada. É também o contexto de Guerra Fria e de uma Itália em reconstrução. O cineasta trabalha com imagens que nos filmes apresentam-se mais fundamentais que a própria trama (enredo). As imagens compõem a essência fílmica, o que resulta por vezes em narrativas tensas e lentas, quase circulares.

É assim na trilogia da incomunicabilidade. Composta pelos filmes A Aventura (1960), A Noite (1961) e O Eclipse (1962), os filmes trazem personagens alienados, que plainam sem raízes sobre um solo quase sempre desconhecido. Não se aborda lugares densos de memória das personagens, são espaços de visita, passagens, sobrevoos, espaços vazios. Na montagem, predomina a forma elíptica, e há poucas relações lógicas ou causais entre as imagens. Há assim uma diluição da trama nas imagens compostas por Antonioni, diluição que provoca uma percepção de que nada acontece nos filmes. A narrativa aberta de Antonioni é complementada pela constância da descentralização dos atores nas cenas, o que faz que os cenários não sejam apenas "fundos", pois eles emergem e constroem ativamente o sentido. O cinema antonioniano é plástico, fundamentado na imagem, a qual não é dependente do enredo, dos personagens ou de uma lógica tradicional de montagem (MATOS, 2007).

Seus quadros são constituídos por uma câmera relativamente fixa em contraposição à variação de quadros, dos quais os personagens transitam, entram e saem, o que ratifica a importância do espaço, da imagem como um todo. O percorrer sem direção dos personagens evoca a questão existencial e o vazio dos mesmos, produzido mediante por esta associação gratuita entre câmera e personagem (MATOS, 2007).

Na trilogia da incomunicabilidade não se tematiza um desejo de silêncio, pelo contrário, os personagens querem estabelecer a comunicação, contudo não conseguem, não podem. A comunicação não se completa e as personagens são profundamente solitárias, mesmo estando em festas, em grupos ou em relacionamentos amorosos (ORICCHIO, 2012).

O primeiro filme da trilogia, A Aventura (1960), um grupo de seis amigos viajam à uma ilha vulcânica na Sicília. Neste grupo está o casal que brigam constantemente, Anna (Lea Massari) e Sandro (Gabriele Ferzetti), e algo surpreendente ocorre: Anna misteriosamente desaparece, sem deixar rastro. O filme se desenvolve a partir do desaparecimento que não é 
explicado. O grupo se divide, e Sandro e Claudia (Monica Vitti) - a melhor amiga de Anna ficam na ilha enquanto seus amigos vão comunicar as autoridades sobre o ocorrido. Há em cenas paisagens vazias, compostas de espaços rochosos da ilha e construções abandonadas. Sandro e Claudia buscam Anna pelas cidades vizinhas e nessa buscam se apaixonam.

A Noite (1961) é sobre um casal Lidia (Jeanne Moreau) e Giovanni (Marcello Mastroianni) que mantém um relacionamento cansado e tedioso. Parece que o único elo possível, o elo comunicativo entre Lidia e Giovanni é a sensação de enfado. A história inicia com uma visita do casal à um amigo à beira da morte num hospital. Em seguida vão à uma festa burguesa em que percorrem a casa do anfitrião como se procurassem algo, alguma experiência que os motive. A longa noite termina com os dois no jardim e uma possível reconciliação, mas que não é capaz de superar a fadiga do relacionamento.

Em O Eclipse (1962), Vittoria (Monica Vitti) termina o namoro com Riccardo (Francisco Rabal) e vai visitar sua mãe no trabalho, na Bolsa de Valores. Lá se depara com o ambicioso Piero (Alain Delon), por quem se apaixona, embora inicialmente tentasse evitar o sentimento. As personagens e o relacionamento vazio é correlacionado com cenas da cidade em transformações motiva pelo período de reconstrução da Itália após a Segunda Guerra.

$\mathrm{Na}$ trilogia, Antonioni explora a angustia das personagens, suas crises de existir, confrontando tais sensações com passagens desérticas, abandonadas, promovendo a dissolução das individualidades nas paisagens. Como Deleuze (2007) nos diz, as palavras se elevam no ar, e a terra afunda, cada vez mais. $\mathrm{O}$ visual traz a tona o vazio em que o tempo impera, onde o tempo racha os próprios personagens.

\section{AS FIGURAS DO TEMPO}

Como vimos, para Deleuze, a categorização clássico/moderno tem a ver com a apresentação indireta ou direta do tempo nas imagens. Não é uma questão de periodização histórica. A questão não está numa distinção histórica entre cinema clássico e moderno. Deleuze (2005, p. 354) é categórico: "a imagem-movimento não nos dá uma imagem-tempo".

Assim, já nas primeiras páginas do livro Imagem-tempo, vários cineastas são comentados ao lado de Michelangelo Antonioni, como Rosselini, Vitorio de Sica, Godard ou Rivette, Bresson e Ozu. Em capítulos que se seguem aos primeiros, virão tantos outros, como Resnais, Kubrick, Cassavetes. Reservado ao capítulo sobre cristais de tempo, o filósofo identifica cineastas e estilos diferenciados para cada cristal, isto é, para cada imagem-cristal que ele define como sendo uma imagem a um só tempo virtual e atual. Temos cristais de Fellini, 
que são cristais em formação, ou bem podemos ter cristais de Visconti, que são cristais em decomposição.

Da enorme gama de cineastas mencionados no livro Imagem-tempo, privilegiamos apenas o italiano Michelângelo Antonioni. Pois o cineasta integra a lista de filmes sugeridos no livro didático de Manini e Roncaglio (2016), por meio do filme Blow-up-depois daquele beijo. E também porque o visionamento de outros dos seus filmes nos permitiu perceber uma estrutura mais ou menos comum na denúncia do tédio e mal-estar da humanidade, mal-estar dos personagens atuando como videntes a partir de muito investimento no olhar. Personagens que olham tudo sem reação, tão grande é sua necessidade de ver corretamente o que há na situação.

Outra de nossas justificativas na escolha de Antonioni como exemplo de imagem-tempo é que muitos dos comentários deleuzianos sobre o cineasta integram o primeiro capítulo do livro Imagem-tempo. É que já tínhamos nos debruçado no segundo capítulo, chamado "Recapitulação das Imagens e dos Signos", registrado em Mostafa e Pierce (2012), o que nos valeu um aprofundamento nos signos do tempo ausentes na tricotomia de Charles Peirce. Aqui nesta oportunidade queremos aprofundar a problemática do neorrealismo italiano.

Ao comentário de Antonioni sobre a doença de Eros (MOSTAFA; AMORIM; SABBAG, 2018), Deleuze acrescenta outra: Cronos é doença. Significa que Antonioni introduz uma patologia que corrompe a ação dramática dos personagens, e tal patologia é a doença da temporalidade. Os personagens são atravessados pelo tempo. Fissurados e divididos pelo tempo. Ou pelos dois sujeitos pensados por Kant no primeiro livro sobre a filosofia crítica: o eu empírico e o eu transcendental.

A grandeza de Antonioni é mencionada por Deleuze pelo fato de o cineasta ter mostrado a patologia do tempo, não apenas no contexto do cinema, mas a partir do cinema. O cinema moderno inventa, então, essa introdução do tempo nas imagens, tempo que atordoa e desabilita os personagens de qualquer ação motora. A filosofia crítica de Kant é também chamada de filosofia transcendental justamente por Kant ter pensado o tempo, pela primeira vez, fora da sua relação com o movimento, e, portanto, fora da relação com o espaço. O tempo é um a priori. Ou, como diz Kant, uma categoria a priori da sensibilidade. Nós só podemos sentir o tempo intuitivamente. É essa anterioridade do tempo que constitui a sua transcendência (KANT, 1958).

Os filmes de Antonioni dos anos 1960 e início da década de 1970 podem ser situados nessa linha quase kantiana. O cineasta empreende uma crítica objetiva do indivíduo, mas, no fundo de sua sintomatologia, descobre a doença da temporalidade. Diz Deleuze que, para Antonioni, só há doença crônica. Cronos é a própria doença. Comenta Deleuze (2005, p. 35): 
[...] não somente o ótico e o sonoro, mas o presente e o passado, o aqui e o noutro lugar, constituem elementos e relações interiores que devem ser decifrados, e não podem ser compreendidos senão numa progressão análoga à da leitura [...] mais perto de uma leitura do que de uma percepção.

O cinema moderno tem, na compreensão de Deleuze, uma inspiração kantiana por apresentar esse sujeito moderno rachado pelo tempo. O filósofo francês sugere que o cinema repete, em seus próprios termos e em condições próprias, a "revolução" que moldou a filosofia moderna. Tanto o cinema quanto a filosofia foram marcados por uma espécie de classicismo entendido como uma subordinação do tempo ao movimento, ou à ordem do número, do espaço e do movimento. Tanto o cinema quanto a filosofia padeceram de uma esquematização sensório-motora dos movimentos. Talvez Deleuze tenha sido o primeiro filósofo a considerar o cinema um tema propriamente necessário para a filosofia ou um tema intrinsicamente filosófico. $\mathrm{O}$ cinema introduz não apenas o movimento real nas imagens, mas também uma nova "forma de tempo" no pensamento, e essa visão inscreve uma história do cinema moderno que ressoa na história da filosofia.

As razões do colapso do vínculo sensório-motor nas imagens são complexas e tanto Deleuze quanto Antonioni mencionam fenômenos como a Segunda Guerra Mundial, a turbulência econômica, a descolonização, bem como a proliferação global de imagens, propagandas e clichês. Levadas à exaustão, essas figuras promoveram um saturamento ou esgotamento e, como filósofo, Deleuze elabora o conceito epônimo no seu segundo livro sobre cinema: a "imagem-tempo", traçando uma nova ideia de cinema baseado no movimento aberrante e no corte irracional.

[...] quando o cinema faz sua revolução kantiana, quer dizer, quando ele deixa de subordinar o tempo ao movimento, quando faz o movimento depender do tempo (o falso movimento com apresentação das relações do tempo), então a imagem cinematográfica torna-se uma imagem tempo, uma autotemporalização da imagem (DELEUZE, 1992, p. 84).

Se essa proposta do filósofo ainda é difícil de entender após 30 anos do lançamento dos seus livros de cinema, é porque talvez ainda não tenhamos entendido o que significa dizer que o cinema do pós-guerra se tornou kantiano. Como pode um fenômeno no século XX estar recebendo uma inspiração do século XVIII? Também não é tão clara essa filiação em termos de explicação teórica nos livros de cinema, mas em O que é filosofia? Deleuze e Guattari (2010) pontua as diferenças entre o cogito cartesiano e o cogito kantiano. No "eu penso, logo existo", de Descartes, notamos três figuras que se comportam como verbo: penso, existo, sou. Kant também terá que dizer "eu penso" dois séculos após Descartes, mas já será um cogito bem diferente do cartesiano. Pois o eu que pensa de Kant é um eu atravessado pelo tempo. E o tempo produz reticências no "Eu". Eu penso... eu que também sou um outro... 
Em Crítica e clínica Deleuze (1997, p. 36) sugere as três figuras do tempo presentes na filosofia de Kant, lembrando a fórmula do poeta Rimbaud (1854-1891): “eu é um outro”. Ainda cogita se a fórmula de Kant seria a via de conversão do eu em outrem, ou se é uma preparação para a chegada de Rimbaud, tão forte é o deslizamento que o "eu” vai experimentar daí para a frente. Deleuze (1997) resume a filosofia kantiana em quatro fórmulas poéticas:

- O tempo está fora dos gonzos (Shakespeare, Hamlet I, 5);

- Eu é um outro (Rimbaud);

- Que suplício ser governado por leis que não se conhecem (Kafka, A muralha da China);

- Rimbaud (chegar ao desconhecido pelo desregramento de todos os sentidos [...] um longo, imenso e racionado desregramento de todos os sentidos).

Em 1871, o poeta Rimbaud escreve uma carta a seu mestre Izambard que se tornou mais importante para a filosofia que a sua própria poesia. Na carta, Rimbaud rejeita imagens de interioridade e aposta tudo na sua poesia objetivista:

\begin{abstract}
Quero ser poeta e trabalho para tornar-me vidente: o senhor não compreenderá de modo algum e eu quase não poderei explicar-lhe. Trata-se de chegar ao desconhecido pelo desregramento de todos os sentidos. Os sofrimentos são enormes, mas é preciso ser forte, ter nascido poeta, e eu me reconheci poeta. Não é absolutamente minha culpa. Está errado dizer: Eu penso. Deveríamos dizer: Pensam-me. Perdão pelo jogo de palavras. EU é um outro. Azar da madeira que se descobre violino, e danem-se os inconscientes que discutem sobre o que ignoram completamente! O senhor não é professor para mim (RIMBAUD apud MOSTAFA; NOVA CRUZ, 2009, p. 37).
\end{abstract}

Kant foi para Deleuze um intercessor curioso, amado e rejeitado ao mesmo tempo. Deleuze admirou três aspectos da filosofia de Kant, segundo Mostafa (2008, p. 21): a concepção do sublime na terceira crítica; o carácter problemático da Ideia: ideias são problemas e sem problemas não há ideias; e a concepção do tempo. Segundo Deleuze, Kant conseguiu desenrolar o tempo, colocando-o em linha reta, na medida em que ele agora não precisa acompanhar as voltas espaciais do movimento.

A rejeição deve-se ao esquematismo kantiano, pois as categorias do entendimento também são a priori e, portanto, não passam pela experiência concreta. Examinar as condições de possibilidade da razão para o aparecimento de objetos, sem tocar nos valores vigentes, parece comprometer a crítica kantiana ao senso comum da sua época. É isso que faz Deleuze substituir o crítico legislador kantiano pelo crítico legislador nietzschiano, esse que avalia e julga, mas cria valores novos e novas maneiras de sentir e pensar.

Nossa percepção passa, segundo Kant, pelas faculdades humanas que são a sensibilidade, o entendimento e a razão. Para Kant (1958), intuímos espaço e tempo; uma vez 
situados espaço-temporalmente, percebemos os objetos do mundo tal como eles se apresentam para nós (é uma fenomenologia), pois nosso entendimento é equipado com categorias também a priori e antes de qualquer experiência: quantidade, qualidade, relação e modalidade. Tudo que podemos conhecer se circunscreve pela sensibilidade e pelo entendimento. As questões metafísicas sobre o infinito, ou as "coisas em si" são incognoscíveis para a razão. O fenômeno é cognoscível, mas o númeno, não é possível conhecê-lo. Kant chama revolução copernicana a essa capacidade a priori do entendimento humano de levar para a realidade as categorias de ordenamento do mundo. Analisa as condições de possibilidade do aparecimento de objeto para nós. Uma análise da razão pela razão. Deleuze rejeita as limitações impostas pela razão, acusando Kant de ter pensado o transcendental a partir do empírico; explode com o númeno e substitui o par fenômeno-númeno pela relação entre virtual e atual. Fala-nos de um empirismo transcendental ou superior, contrapondo-se ao idealismo transcendental kantiano. E convocanos a enfrentar o infinito. Não há ciência, arte ou filosofia sem esse enfrentamento ao caos.

Pois bem, nas figuras poéticas resumidas por Deleuze sobre a filosofia crítica de Kant, especialmente a fórmula de Rimbaud "eu é um outro", este "eu", para Kant, é passivo e determina nossa existência como um eu passivo e mutante no tempo. E diz Deleuze (1997, p. 40): “o tempo é esta relação formal segundo a qual o espírito se afeta a si mesmo ou a maneira pela qual somos interiormente afetados por nós mesmos. O tempo poderá ser definido como o Afeto de si por si, ou pelo menos, como a possibilidade formal de ser afetado por si mesmo".

Daí que o tempo fica sendo uma forma de interioridade, e o "espaço aparece, por sua vez, como forma de exterioridade, possibilidade formal de ser afetado por outra coisa enquanto objeto externo" (DELEUZE, 2007, p. 103). Mas forma de interioridade não significa que o tempo é interior ao espírito, pois, alerta Deleuze, o espaço também o é. Deleuze (2007) dirá, conforme sua inspiração bergsoniana e na contramão de Kant, que somos nós que estamos no tempo, "nós é que somos interiores ao tempo, e a esse título, sempre separados por ele, daquilo que nos determina afetá-lo".

Pois bem, o visionamento de cinco filmes de Antonioni dos anos década de 1960 com a trilogia da incomunicabilidade (1960 a 1963) e Blow-up - depois daquele beijo (1966), terminando com Passageiro: profissão repórter (1975) permite dizer que o cineasta, nas décadas de 1960 e 1970, preenche as figuras kantianas da temporalidade, daí a tese defendida por Flaxman (2015) relacionando Deleuze, Antonioni e as raízes kantianas do cinema moderno.

A primeira figura sugerida por Deleuze sobre o tempo em Kant é que o tempo está fora dos eixos, na famosa frase de Hamlet. Ora, as cenas filmadas por Antonioni, em geral, começam muito tarde, e as tomadas continuam por muito tempo após os diálogos ou gestos ensaiados. Os 
períodos ociosos não mostram apenas as banalidades da vida cotidiana, mas colhem os efeitos ou as consequências do que se passou. Acontecimentos notáveis como a separação de um casal ou o desaparecimento de uma mulher são mostrados em termos de efeitos: quando tudo já foi dito e a cena parece terminada, há o que vem depois e é esse "depois" que parece ser o problemático para Antonioni. Aí reside a Ideia ou o pensamento do seu cinema.

Em $A$ aventura, $A$ noite e $O$ eclipse, o uso intenso de plano-sequência não consolida o espaço como tal, mas, ao contrário, ficamos com espaços fragmentados, pois a conexão entre eles não é dada, o que causa a sensação de uma linha do tempo fora dos gonzos. O tempo está fora dos eixos nos filmes de Antonioni. À fórmula kantiana do tempo como uma forma vazia e imutável, mas que faz tudo mudar, podemos pensar nas imagens do deserto ou mesmo nas imagens urbanas, em que o cineasta desenquadra as imagens mais do que as enquadra. Evacuar os personagens da cena é uma forma de desenquadramento; ausência de personagens e forte presença da câmera causam a sensação de planos vazios. Desenquadrar não significa apenas deslocar objetos e corpos para a lateral do quadro, como já apontamos ser uma das características das imagens-tempo de Antonioni, mas também simplesmente enquadrar o vazio, como observa Oliveira (2008).

Deleuze (2005, p. 14) observa que "a arte de Antonioni se desenvolverá sempre em duas direções: uma espantosa exploração dos tempos mortos da banalidade cotidiana; depois, a partir de $O$ eclipse, um tratamento das situações-limite que as impele até paisagens desumanizadas, espaços vazios", espaços que teriam absorvido as personagens e as ações, deixando o espectador apenas com a descrição geofísica do lugar, como já pudemos observar na ilha vulcânica de $A$ aventura. Mas também na perambulação de Lídia no filme $A$ noite, assim como nas fantásticas cenas finais de O eclipse, "onde os espaços desconectados do espaço vivido pela heroína, Bolsa, África, aeroporto, somam-se no final do filme em um espaço vazio que se confunde com a superfície branca" (DELEUZE, 2005, p. 14). O personagem desapareceu não simplesmente por estar fora do quadro, mas por ter sido absorvido pelo vazio ou pela imensidão espacial. Na ilha vulcânica, tanto os personagens que são vistos quanto os que veem estão a ponto de desaparecer. O cinema moderno trata o espaço como um espaço-qualquer que seja proporcional à forma vazia do tempo. E é nesse intervalo entre o espaço habitado e os seus efeitos sobre nós que veremos nascer o tempo, não como o que se passou, não como um fato histórico, mas como acontecimento. $\mathrm{O}$ vivido não como um acontecimento histórico, mas como um tornar-se. Ou isto em que estamos nos tornando. Pois afetamos e somos afetados no acontecimento. Envelhecemos e rejuvenescemos no acontecimento enquanto acontece. É a 
afetação do tempo. Ou o tempo como afeto de si por si. Somos todos afetados pelo tempo, o tempo todo. Importa o daqui para frente do que se passou. Importa o devir.

O confronto entre essas duas figuras do tempo - o tempo fora dos eixos e o que isso provoca em nós -, a imagem-tempo também comporta a terceira figura "Eu sou um Outro" no filme $O$ passageiro: profissão repórter. A história de um homem que tenta se perder. $\mathrm{O}$ personagem ouve uma conversa (gravada) dele mesmo com outro já morto, ao mesmo tempo em que planeja ocupar a identidade do morto. Em uma única tomada, a linha do tempo bifurcase, impulsionando-nos em duas direções: um passado em que o personagem Locke, o repórter, se queixa das convenções (somos nós que somos os mesmos e temos os mesmos códigos) e uma linha de futuro (como será a vida que ele vai assumir?). Nesse momento, Locke não é mais ele mesmo, pois ele é pelo menos dois, segundo a fórmula de Rimbaud "Eu sou um Outro".

"O tempo fora dos eixos", "o afeto do eu por si mesmo" e "eu sou um outro" são expressões de três tipos de imagem-tempo que caracterizam o cinema e a filosofia modernos.

\section{INDEXAÇÃO DE ASSUNTO E CINEMA}

Como trazer para a Ciência da Informação esses ensinamentos filosóficos do cinema? Conceitos filosóficos (do cinema) trabalhados aqui como imagem-movimento, imagem-tempo, imagem-ação, imagem-reação, imagem-afeto, imagem-cristal, cristais do tempo, figuras do tempo como é o título desta reflexão são todos conceitos que precisam ser convertidos em termos de indexação. Para não ficarmos apenas com a noção de gêneros fílmicos, onde categorias como drama ou filmes de pós-guerra que seriam categorias por demais gerais para descrever as relações do tempo com as imagens. As análises de cinema realizadas por Deleuze estão baseadas no filósofo Henri Bergson, de maneira que, além de um certo quase-kantismo, podemos pensar em certo bergsonismo como termo válido para indexar imagens-tempo, como sugerido em outra oportunidade (MOSTAFA; MANINI, 2017a).

Mostafa e Manini (2017a) afirmam que muito das teorias fílmicas são consideradas pelos profissionais no ato de indexar os filmes, contudo elementos de tais teorias podem ser proveitosas nos processos de leitura e análise documentária. As autoras apresentam um conjunto de conceitos filosóficos presentes em Deleuze $(1985$; 2005) que corroboram a indexação de filmes: 
Quadro 1: Classificação das imagens cinematográficas segundo Deleuze

\begin{tabular}{|l|l|}
\hline \multicolumn{1}{|c|}{ Imagem-movimento } & \multicolumn{1}{c|}{ Imagem-tempo } \\
\hline Variação universal das imagens & Variação universal das imagens \\
\hline Esquema sensório-motor & Situações óticas e sonoras puras \\
\hline Reconhecimento automático & Reconhecimento atento \\
\hline Racionalidade dos cortes & Cortes irracionais \\
\hline Narração orgânica & Narração cristalina \\
\hline Aspiração ao verídico & Potência do falso \\
\hline
\end{tabular}

Fonte: MOSTAFA; MANINI (2017a)

Mostafa, Amorim e Sabbag (2018) acrescentam a noção de cristal do tempo e reforçam a importância do indexador compreender as diversas imagens que compõe um filme. Tal recomendação implica na incorporação de novas preocupações ao rol dos estudos de indexação, pois tradicionalmente seu processo enfoca as questões conceituais e linguísticas (saussureanas). Esse olhar tradicional não dâ conta da indexação de documentos imagéticos e fílmicos, pois esses requerem a atenção à dimensão do afeto, sobretudo no universo artístico. Para além do conceito e do signo linguístico, o afeto pode contribuir nas teorias e metodologias do tratamento temático dos documentos. Conceitos como informação-afeto (MOSTAFA; NOVA CRUZ, 2009) revelam essa potência.

Nada impede que os conceitos filosóficos possam por si mesmos tornarem-se termos para a indexação fílmica, mas acreditamos que a partir dos termos presentes no quadro 1, uma variada gama de novos termos possam surgir, compondo o que passou-se a chamar, desde 2010 de Linguagem Documentária Menor, conceito/termo possibilitador de um ciclo de experimentação, incluindo análises de cinema, fotografia, filosofia e sua relação com a ciência da informação (MOSTAFA; MANINI, 2017a; MOSTAFA; AMORIM; SABBAG, 2018).

As imagens cinematográficas variam entre cineastas mas é possível perceber um estilo imagético em cada grande artista. Nos dois livros de Deleuze (1985; 2005) sobre cinema é apresentado uma grande quantidade de cineastas e filmes, associados à uma variedade de imagens que podem ser úteis ao processo de indexação. A Ciência da Informação é potencializada no deslizamento de planos, no contato com o não-científico, com o filosófico e o artístico. Dessa forma, sugerimos outros caminhos para a indexação, um caminho que não priorize a representação documental compreendida sob o olhar representacionista, mas que, ao invés de representar, apresente. Apresentar possibilidades de afetos que um filme ou documento qualquer possa causar nos usuários, na medida em que estabelece diálogos de abertura que viabilizem o conhecimento e o pensamento. 


\section{REFERENCIAS}

DELEUZE, G. A lógica do sentido. São Paulo: Perspectiva, 2007.

DELEUZE, G. Bergsonismo. São Paulo: Ed. 34, 1999.

DELEUZE, G. Cinema 1: a imagem-movimento. São Paulo: Brasiliense, 1985.

DELEUZE, G. Cinema 2: a imagem-tempo. São Paulo: Brasiliense, 2005.

DELEUZE, G. Conversações. Rio de Janeiro: Ed. 34, 1992.

DELEUZE, G. Crítica e clínica. Rio de Janeiro: Ed. 34, 1997.

DELEUZE, G. O ato de criação. Folha de São Paulo, v. 27, p. 4, 1999. Disponível

em: $<$ http://www.filoczar.com.br/filosoficos/Deleuze/Gilles\%20Deleuze\%20-

\%20O\%20ato\%20de\%20Cria\%C3\%A7\%C3\%A3o.pdf >. Acesso em: 22 abr. 2015.

DELEUZE, G.; GUATTARI, F. O que é a filosofia?. São Paulo: Ed. 34, 2010.

FLAXMAN, G. The brain is the screen: Deleuze and the philosophy of cinema. University of Minnesota, 2000.

KANT, E. Crítica da razão prática. 3.ed. São Paulo: Brasil Editora, 1958.

MACHADO, R. Deleuze, arte e filosofia. Rio de Janeiro, Zahar, 2009.

MANINI, M. P.; RONCAGLIO, C. Arquivologia \& cinema: um olhar arquivístico sobre narrativas fílmicas. Brasília: Ed. UnB, 2016.

MATOS, Y. A. V. F. A crônica visual de Michelangelo Antonioni. 2007. Tese (Programa de Pós-Graduação em Filosofia) - Universidade de São Paulo, São Paulo, 2007.

MOSTAFA, S.P.; CHARLES P. Gilles Deleuze a e Ciência da Informação. Informação \& Sociedade: Estudos, João Pessoa, v. 22, n. 1, p. 27-37, 2012.

MOSTAFA, S. P.; AMORIM, I. S.; SABBAG, D. M. A. Eros e a Ciência da Informação. Em Questão. No prelo (2018).

MOSTAFA, S. P.; MANINI, M. P. Imagem, memória e informação: o bergsonismo na ciência da informação. Revista Conhecimento em Ação, v. 2, n. 1, p. 2-18, 2017 b.

MOSTAFA, S. P.; MANINI, M. P. O Blow Up da Ciência da Informação. Pesquisa Brasileira em Ciência da Informação e Biblioteconomia, v. 12, n. 1, 2017a.

MOSTAFA, S. P.; NOVA CRUZ, D. V. Para ler a filosofia de Gilles Deleuze e Félix Guattari. Campinas: Alínea, 2009.

MOSTAFA; NOVA CRUZ, D. V. Para ler a filosofia de Gilles Deleuze e Félix Guattari. Campinas: Alínea, 2009. 
OLIVEIRA, R. A. Antonioni e a trilogia da incomunicabilidade (I). Blog Cineplot. 2008. Disponível em: < https://cinemaitalianorao.blogspot.com.br/2008/02/antonioni-e-trilogiada.html >. Acesso em: 10 jan. 2017.

ORICCHIO, Luiz Fernando Zanin. A trilogia da incomunicabilidade de Antonioni. Blog Luiz Zanin: Cinema, cultura \& afins. Estadão. 06 Agosto 2012|00h11. Disponível em : $<$ http://cultura.estadao.com.br/blogs/luiz-zanin/a-trilogia-da-incomunicabilidade-deantonioni/>.

\section{FILMOGRAFIA}

A Aventura. [longa-metragem] Dir. Michelangelo Antonioni. Cinematografiche Europee Société Cinématographique Lyre. França, Itália, 1960. 135mins.

A Noite. [longa-metragem] Dir. Michelangelo Antonioni. Nepi Film - Sofitedip e Silver Film. Itália, França, 1961. 122mins.

Blow Up: depois daquele beijo. [longa-metragem] Dir. Michelangelo Antonioni. Carlo Ponti ppela Metro Goldwyn Mayer. Reino Unido; Itália, 1967. 110mins.

O Eclipse. [longa-metragem] Dir. Michelangelo Antonioni. Interopa Film - Cfineriz - Paris Film Production. França, Itália, 1962. 125mins.

O Passageiro, profissão repórter. [longa-metragem] Dir. Michelangelo Antonioni. Sony Classics. Espanha, Estados Unidos, França, Itália, 1975. 126 mins. 